\title{
Software for Annotating Videos-A Resource to Facilitate Active Learning in the Digital Age
}

\author{
Kalyani Premkumar ${ }^{1}$, Niel Cowie ${ }^{1}$, Cyril M. Coupal ${ }^{2}$, Kevin Boechler ${ }^{2}$ \\ ${ }^{1}$ College of Medicine, University of Saskatchewan, Saskatoon, Canada \\ ${ }^{2}$ Information and Communications Technology, University of Saskatchewan, Saskatoon, Canada \\ Email: kalyani.premkumar@usask.ca
}

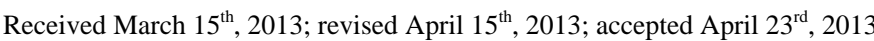

\begin{abstract}
Copyright @ 2013 Kalyani Premkumar et al. This is an open access article distributed under the Creative Commons Attribution License, which permits unrestricted use, distribution, and reproduction in any medium, provided the original work is properly cited.
\end{abstract}

\begin{abstract}
In many areas of study-especially health professions, visual demonstration of concepts, processes and procedures form an important strategy for teaching and learning. Video recordings can be invaluable in capturing visual components. Annotations add another all-important dimension to the learning value of the video. Our Annotated Video Software is an innovative e-learning tool in support of experiential and self-directed learning. Annotations are independent of the video and the separation of annotation and video provides a robust learning environment that supports content. The tool is user-friendly and instructors can add annotations, without the need for intervention by programmers. Annotations can consist of notes of explanation, complementary videos, links to additional information and questions to engage critical thinking. Students' answers to questions may also be collected and collated. Upon submission of answers feedback can be displayed, thus transforming evaluation into an immediate learning opportunity. We have already created educational resources for health professionals. Next steps include dissemination of the software to educators, provision of software access by mobile devices and better strategies to incorporate the annotated videos into existing learning management systems.
\end{abstract}

Keywords: Video Annotations; Instructional Design; E-Learning; Active Learning

\section{Introduction}

Since the hours available in a day have not increased to accommodate the growth of knowledge in every sphere of education, the only realistic alternative is to improve utilization of students' time by embracing learning strategies that are selfpaced, competency-based, engaging, that use educational principles that improve retention (Prober, 2012). Research has identified a number of factors that help with engagement and retention of information. For instance, in medicine, patient casespaper or otherwise, are used to help students situate the information to be learned in context. It is well known that information is retained longer if it is in the form of patient stories, elicits emotions in the learner, is professionally relevant and evokes curiosity (Moon, 2010). In higher education, podcasts and lecture recordings are made available to enable students to learn at their own time and at their own pace (Prober, 2012).

Apart from using sound educational principles, the nature of students in this era has forced educators to re-examine mode of delivery. Students of the Net Generation (also known as Millenneals, born between 1982-1991) consider technology vital to education (Prensky, 2001). Technology is helpful to absorb abstract concepts easily and faster, it allows students to learn as much as they want virtually about any topic and connect with friends to help or get help (Threshold, 2004). Net Generation students have been described as intuitive visual communicators with the ability to weave images, texts and sound naturally. They have high visual-spatial skills, and learn better through discovery by themselves or with peers (Oblinger \& Oblinger, 2005; Prensky, 2001). They crave interactivity and are more comfortable in image-rich environments than text. There is evidence to support that many hours devoted to playing video games and watching TV up to College graduation have physically changed brain pathways in these digital native students (Prensky, 2001).

Since the Net Generation grew up with interactive video games, social media, video-on-demand, and educational interactive multi-media, they expect the educational environment to be similar, and tend to loose interest very quickly if taught in the traditional talk-text-test environment (Howe \& Stauss, 2000). Given the social nature of the net generation, affinity for visual environment and preference for experiential learning, video technology can serve as a useful tool for teaching and learning.

\section{Broadcast Video and Learning}

Videos are the most common media used in educational settings (Merkta, Weigand, Heier, \& Schwan, 2011) and are likely to be used more extensively with the availability and affordability of video production and editing tools. Video has been shown to be an effective learning tool in many educational disciplines (Shepard, 2003). Video imparts much more than explicit factual information. Not only is "a picture worth a thousand words", but a video is worth much more than that, since it has the power to express the implicit subtleties of emotion and character interaction that is key to understanding the 
way in which, for example, medical problems evolve or are managed. In a multi-step procedure, video is extremely helpful in isolating each step and imparting information that simple text would be unable to fully describe economically.

Videos provide visual dynamic effects that are particularly helpful for learning dynamic processes (Be'trancourt \& Tversky, 2000). They have the capacity to combine multiple modalities such as text, pictures and audio that can be advantageous based on Paivio's dual-coding theory (Paivio, 1969; Paivio, 1971). According to this theory, verbal and pictorial codes are processed in functionally independent but interconnected channels that integrate later. When these two contents complement each other and overlap, they enhance retrieval and recall. Videos can take advantage of the modality principle which states that pictures and spoken words are superior to pictures and texts in terms of recall and retention (Paivio, 1969; Paivio, 1971; Mayer, 2001; Mayer \& Chandler, 2001; Leahy \& Sweller, 2011; Sweller, van Merrienboer, \& Paas, 1998).

The use of trigger films (TF) or videos of very short duration is another teaching and learning strategy commonly used to facilitate learning. A TF is defined as a 2 to 4 minute cinematographic vignette that simulates a real-life situation, the interpretation and analysis of which can take place later in a safe learning environment (Baud \& Pearson, 1979; Alroy \& Ber, 1982; Hartland, Biddle, \& Fallocaro, 2008). Adult learning theories support that not only do humans learn from their own mistakes, but that they can learn vicariously from observing the successes and failures of others (Clark \& Paivio, 1989) and TFs promote such learning.

In addition to the multiple learning benefits, videos have some limitations. Although videos enable consistent delivery of the same videos to all students, no matter whether they are a novice or an expert, they are linear in that they tell a story that has a beginning, middle and end, but contain no metadata to impart additional information to the student. Another drawback is inadequate learner control. The effectiveness of broadcast video with minimal learner control has been questioned by many (Furnham, Benson, \& Gunter, 1987; Furnham \& Gunter, 1985; Walma van der Molen \& van der Voort, 1997, 2000).

Knowledge acquisition using such video has been shown to be inferior to that of print especially for learning complex and semantically rich content (Schnotx \& Kurschner, 2008). One of the reasons cited for this difference is the lack of control the viewer has in altering the pace and sequence of information flow according to cognitive abilities. There is evidence to show that learning is improved if the learner is given even simple control such as stop and start of video (Hasleer, Kersten, \& Sweller, 2007). Learning is also enhanced if the learner has control over the sequence (Wouters, Paas, \& van Merriënboer, 2010; Wouters, Tabbers, \& Paas, 2007; Schwan \& Riempp, 2004). In print, readers are able to manipulate the content in a number of ways such as skip information, reread difficult and complex content. On the other hand, in broadcast videos, because the information is transient, there is scope of cognitive overload of short-term memory if there is mismatch between the video pace and cognitive capabilities of the viewer (Merkta et al., 2011). According to Lowe (2004), such a mismatch can lead to poor learning outcomes and lower retention of information. A number of strategies such as cuing i.e. highlighting relevant information (de Koning, Tabbers, Rikers, \& Paas, 2007), breaking up the video into segments (Mayer, 2001; Mayer \&
Chandler, 2001; Hasler et al., 2007) have been used in videos and animations to reduce this mismatch. However, it may not be useful for all types of learners and situations as, those with high working memory capacity may not require segmentation (Lusk, Evans, Jeffrey, Palmer, Wikstrom, \& Doolittle, 2009) and short videos may not require cuing (de Koning et al., 2007). Interactive videos have been found to be superior to broadcast videos.

\section{Interactive Videos}

A review of the usefulness of interactive videos in educational settings (Wetzel, Radtke, \& Stern, 1994) concludes that the higher the level of interactivity, higher the accomplishments by learners. Interactivity can be in a variety of ways such as questioning, giving learner feedback and allowing for learner control. Recent studies have shown that students learn better with interactive videos (Schwan \& Riempp, 2004) and require less time to learn complex skills. Given these findings, a number of interactive videos are available to learners, especially in health professions (Daetwyler, Cohen, Gracely, \& Novack, 2010; Cook, Erwin, \& Triola, 2010; Chu, Young, Zamora, Kurup, \& Macario, 2010; Barbarav, 2008; Magenheim, Reinhardt, Roth, Moi, \& Engbring, 2010; Meixner et al., 2009). Software has been developed that combines streaming video with teacher initiated and student initiated annotations. Such programs allow students to record audio comments or enter written comments that pertain to video segments (Barbarav, 2008; Magenheim et al., 2010). This technology has opened up the option where students can share comments with each other and with the teachers (Magenheim et al., 2010).

In medicine, videos with annotations are used to help students learn communication skills (Daetwyler et al., 2010; Cowie et al., 2012), improve diagnostic skills (Cook et al., 2010; Chu et al., 2010), among others. With annotations, the video becomes non-linear, enabling the teacher to assist the student's interpretation of video. However, these annotated videos are standalone packages, typically crafted using HTML programming of webpages that require professional programmers for even minor modifications to the learning resource. As such, the same video cannot be easily reused to train higher level trainees by modifying the content depth of the annotations.

We have developed an annotated video player (AVP) that allows instructors and/or students to attach annotations such as explanatory text, audio or a link to other multi-media information annotate videos without the help of programmers.

\section{University of Saskatchewan's Annotated Video Player Software}

The AVP was developed to 1. Enhance broadcast videos with interactions 2. Help instructors to easily create interactive educational resources using existing videos without the intervention of programmers 3. Allow recycling of existing videos among multiple levels of trainees by keeping the creation of annotations and the video independent of each other. This enables instructors to use the same video, but alter the annotated content according to trainee level. The productions take the form of a playlist of videos presented in a portion of the screen with interactive annotation material appearing in the surrounding screen regions at prescribed times (Figure 1).

Annotations can be in the form of: 


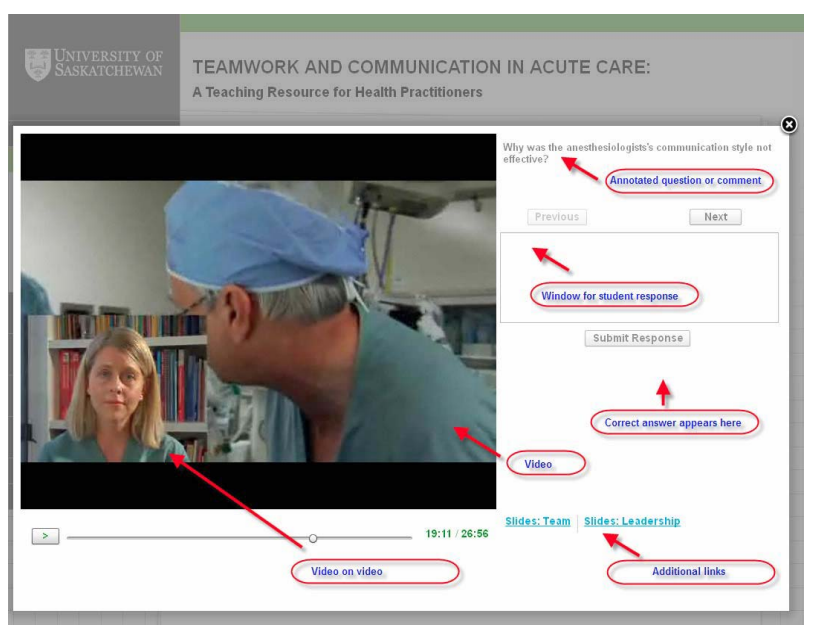

Figure 1.

A screenshot of the annotated bibliography.

- Links to information presentable in a browser window e.g., webpages and pdf documents

- Links to additional videos

- Timed images i.e. static images delivered over a specific time as seen in slideshows

- Text comments

- Quizzes

AVP is an online program that can be accessed using a preferred browser such as Firefox, Chrome, Safari. The AVP program displays three basic views: producer, facilitator and selfdirected learner (SDL). In producer view the user is able to watch, create, modify, and delete a production's content. In facilitator or SDL view one can only navigate media in the playlist and interact with the annotations presented by the production.

\section{Producer View}

In this view, the producer can organize the media items to be annotated in a playlist (Figure 2).

Producers can navigate between and within each media item in the playlist. Once a media item has been added to the playlist the producer can attach annotations to specific points called cues, during the media's playback. The productions only maintain media location, annotation locations and cues, so all original media is untouched and can be reused. Like bookmarks or links in a browser, locations may change. The system provides the mechanism to update locations in a production should they change. Comments and quizzes are stored by the system in a fixed location.

\section{Facilitator and SDL Views}

The facilitator and SDL both restrict the user to navigating the productions content and interacting with the annotations. The facilitator view is designed to be used where an individual is presenting a production to an audience. The facilitator is not able to respond to quiz questions or receive the suggested answer feedback. The SDL view is designed to be used by an individual as an instructional resource. The learner must respond to quiz questions to receive the suggested answer feedback. Individual's responses are saved for reporting purposes.

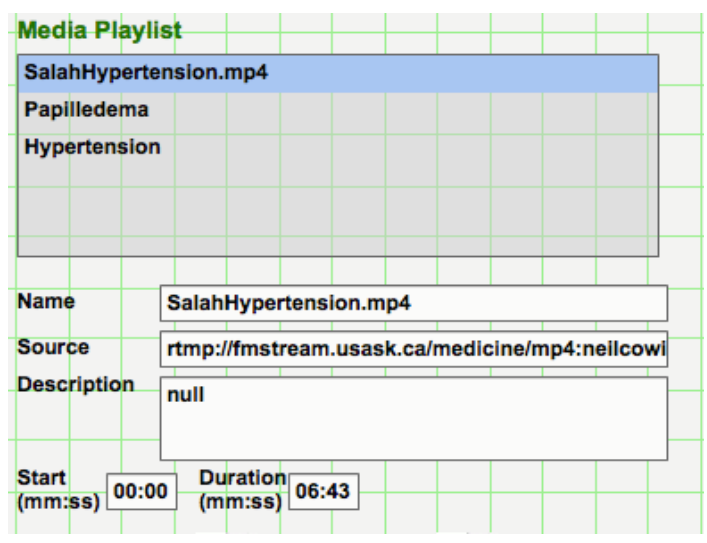

Figure 2.

A snaphot of the producer view.

\section{Operation of Software}

A production is based upon a primary video. That video (either MP4 or FLV) must first be loaded into the streaming server by accessing the URL. Similarly, any other videos to be linked to the original should be loaded into the server.

The managing producer/student view is separate from the streaming server site, and accessed by a different URL. Once the original video files are copied to the folder in the server site, entering the source in the AVP program will link the file name with the original video. The source address follows a specific format for each file type.

- MP4 files need to be entered as

rtmp://fmstream.usask.ca/medicine/mp4:Folder/Filename

- FLV files need to be entered as

rtmp://fmstream.usask.ca/medicine/flv:Folder/Filename

Clicking on the file name in the media playlist will load the video and make it play in the content video screen (Figure 3).

At particular time periods during the video, the producer can insert cue points which will link the video to questions, comments, links to other videos, or other media and links to media on the web.

The student can enter answers in text boxes, to questions posed, click submit, and then be shown the correct answer selected by the teacher. For a more complete understanding, the student can click on a link to access library articles, or references on the web that are given as annotations.

This AVP is an innovative e-learning tool that supports experiential and self-directed learning. The prototype of this software has been showcased to local and international educators and the software has been improved based on their feedback. This software has already been used to create an educational resource on teamwork and communication skills (Cowie et al., 2012). We have embarked upon two projects using the AVP as a proof of concept, with the assistance of two summer students. The first project allowed the student to compile videos already available on You Tube (videos were used with permission). The theme of the videos allowed the student to link in-depth discussion of the topics with credible websites, and with library based articles in pdf format. Comments were used to highlight events on the video that were of interest to the learner, and were usually followed with a link to questions and answers as well as reference material. We are exploring the use of the same videos for creating more complex learning modules for students at 


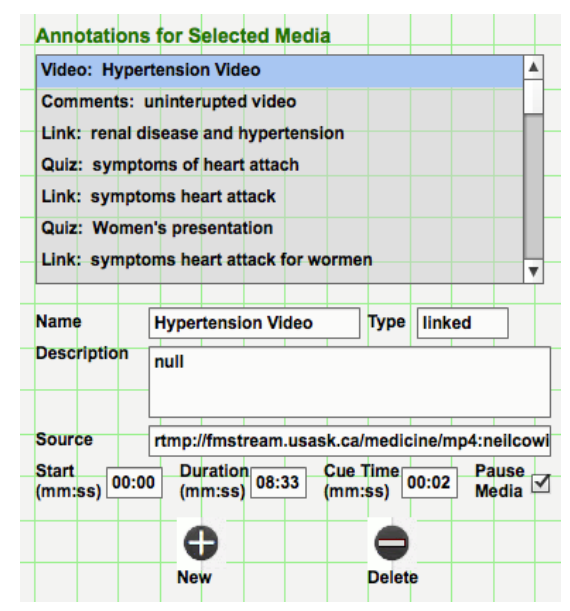

Figure 3.

A snapshot of the content video screen.

a higher level of training. The second project was more expensive, requiring the creation of a video prior to introduction of annotations.

Educators in post-secondary institutions may already have videos that have been used previously for student education. Unfortunately, older videos may cease to be useful for education once the original project is over and exist untouched in library archives. Old videos can become new again when incorporated as learning modules with new links to more contemporary reference material using our AVP.

There is ample scope for our AVP to be used in a variety of situations and areas. For example, the AVP may be used to enhance procedural videos such as placing a central line in the body where not only the procedure is shown, but learners can review the anatomy of a region, learn more about the equipment used, or indications for a central line by a click of a button. Videos of good and bad procedural techniques can be explained in detail using text, links and probe questions. In drama classes, videos of a play could be easily enhanced with director comments, language translations, among others. Educational uses for the AVP can be found for teaching with videos of learners in $\mathrm{K}-12$, higher education and continuing professional learning.

The limitation of this software, however, is the availability of video material. When videos do not exist, the daunting task may be to find resources required to film and edit custom-made videos for the project. Limited server space and slow streaming speed are other barriers to the use of software.

\section{Conclusion}

Our AVP is a tool that can be used for creating interactive resources based on sound educational principles. With the advances of technology and introduction of a variety of mobile devices, access to the video resource by these devices is an issue that needs to be addressed. As more video resources are created using the AVP, mechanisms for sharing the resources and incorporating the resources within existing learning management systems have to be put in place.

\section{REFERENCES}

Alroy, G., \& Ber, R. (1982). Doctor-patient relationship and the medical student: The use of trigger films. Journal of Medical Education,
57, 334-336.

Barbarav, E. (2008). Students' use of video clip technology in clinical education. Top Lang Disorders, 28, 286-298. doi:10.1097/01.TLD.0000333602.76209.e7

Baud, D., \& Pearson, M. (1979). The trigger film: A stimulus for affective learning. Programmed Learning Education Technology, 16, 5256.

Bétrancourt, M., \& Tversky, B. (2000). Effect of computer animation on users' performance: A review. Le Travail Humain: A Bilingual and Multi-Disciplinary Journal in Human Factors, 63, 311-329.

Chu, L. F., Young, C., Zamora, A., Kurup, V., \& Macario, A. (2010). Anesthesia 2.0: Internet-based information resources and Web 2.0 applications in anesthesia education. Current Opinion in Anaesthesiology, 23, 218-227. doi:10.1097/ACO.0b013e328337339c

Clark, J., \& Paivio, A. (1989). Observational and theoretical terms in psychology: A cognitive perspective on scientific language. American Psychologist, 44, 500-512. doi:10.1037/0003-066X.44.3.500

Cook, D. A., Erwin, P. J., \& Triola, M. M. (2010). Computerized virtual patients in health professions education: A systematic review and meta-analysis. Academic Medicine, 85, 1589-1602. doi:10.1097/ACM.0b013e3181edfe13

Cowie, N., Premkumar, K., Bowen, A., Kuling, S., Kawchuk, J., Rooney, M., Morris, G., Burbridge, M., Martel, J., Sivertson, J., Campbell, D., Coupal, C., \& Boechler, K. (2012) Teamwork and communication. Acute Care: A Teaching Resource for Health Practitioners, MedEdPORTAL. www.mededportal.org/publication/9109

Daetwyler, C. J., Cohen, D. G., Gracely, E., \& Novack, D. H. (2010). Learning to enhance physician patient communication: A pilot test of "doc.com" and "WebEncounter" in teaching bad news delivery. Medical Teacher, 32, 381-390. doi:10.3109/0142159X.2010.495759

Furnham, A., \& Gunter, B. (1985). Sex, presentation mode and memory for violent and non-violent news. Learning, Media and Technology, 11, 99-105. doi:10.1080/0260741850110203

Furnham, A., Benson, I., \& Gunter, B. (1987). Memory for television commercials as a function of the channel of communication. Social Behaviour, 2, 105e112.

Hartland, W., Biddle, C., \& Fallocaro, M. (2003). Assessing the living laboratory: Trigger films as an aid to developing, enabling, and assessing anesthesia clinical instructors. AANA Journal, 71, 287-291.

Hartland, W., Biddle, C., \& Fallocaro, M. (2008). Audiovisual facilitation of clinical knowledge: A paradigm for dispersed student education based on Paivio's dual coding theory. AANA Journal, 76, 194198.

Hasler, B. S., Kersten, B., \& Sweller, J. (2007). Learner control, cognitive load and instructional animation. Applied Cognitive Psychology, 21, 713-729. doi:10.1002/acp.1345

Howe, N., \& Strauss, W. (2000). Millennials rising: The next great generation. New York: Vintage Books.

de Koning, B. B., Tabbers, H. K., Rikers, R. P., \& Paas, F. (2007). Attention cueing as a means to enhance learning from an animation. Applied Cognitive Psychology, 21, 731e746. doi:10.1002/acp.1346

Leahy, W., \& Sweller, J. (2011). Cognitive load theory, modality of presentation and the transient information effect. Applied Cognitive Psychology, 25. doi:10.1002/acp.1787

Lowe, R. (2004). Interrogation of a dynamic visualization during learning. Learning and Instruction, 14, $257 \mathrm{e} 274$. doi:10.1016/j.learninstruc.2004.06.003

Lusk, D. L., Evans, A. D., Jeffrey, T. R., Palmer, K. R., Wikstrom, C. S., \& Doolittle, P. E. (2009). Multimedia learning and individual differences.

Merkt, M., et al. (2011). Learning and Instruction. Mediating the effects of working memory capacity with segmentation. British Journal of Educational Technology, 40, 636e651. doi:10.1111/j.1467-8535.2008.00848.x

Magenheim, J., Reinhardt, W., Roth, A., Moi, M., \& Engbring, D. (2010). Integration of a video annotation tool into coactive learning and working environment, key competencies in the knowledge society. IFIP AICT, 324, 257-268.

Martin Merkta, M.,Weigand S., Anke Heier, A., \& Schwan, S. (2011). Learning with videos vs learning with print: The role of interactive features. Learning and Instruction, 21, 687-704. 


\section{K. PREMKUMAR ET AL.}

Mayer, R. (2001). Multimedia learning. Cambridge: Cambridge University Press. doi:10.1017/CBO9781139164603

Mayer, R., \& Chandler, P. (2001). When learning is just a click away: Does simple user interaction foster deeper understanding of multimedia messages? Journal of Educational Psychology, 93, 390e397. doi:10.1037/0022-0663.93.2.390

Meixner, B., Hölbling, G., Stegmaier, F., Kosch, H., Lehner, F., Schmettow, M., \& Siegel, B. (2009). SIVA producer-A modular authoring system for interactive videos. Proceedings of I-KNOW'09 and I-SEMANTICS'092, Graz, 215-225.

Moon, J. A. (2010). Using story: In higher education and professional development. New York: Routledge.

Oblinger, D., \& Oblinger, J. (2005). Is it age or IT: First steps in understanding the net generation. Educating the Net Generation. Educause. http://www.educause.edu/research-and-publications/books/educating -net-generation

Paivio, A. (1969). Mental imagery in associative learning and memory. Psychological Review, 76, 241e263. doi:10.1037/h0027272

Paivio, A. (1971). Imagery and verbal processes. Oxford: Holt, Rinehart \& Winston.

Prensky, M. (2001). Digital natives, digital immigrants, part II: Do they really think differently? On the Horizon, 9, 15-24. http://www.marcprensky.com/writing/ doi:10.1108/10748120110424843

Prober, C. G., \& Heath, C. (2012). Lecture halls without lectures-A proposal for medical education. New England Journal of Medicine, 366, 1657-1659. doi:10.1056/NEJMp1202451

Schnotz, W., \& Kurschner, C. (2008). External and internal representations in the acquisition and use of knowledge: Visualization effects on mental model construction. Instructional Science, 36, 175-190. doi:10.1007/s11251-007-9029-2

Schwan, S., \& Riempp R. (2004). The cognitive benefits of interactive videos: learning to tie nautical knots. Learning and Instruction, 14, 293-305. doi:10.1016/j.learninstruc.2004.06.005

Shepard, K. (2003). Questioning, promoting and evaluating the use of streaming video to support student learning. British Journal of Educational Technology, 34, 295-308. doi:10.1111/1467-8535.00328

Sweller, J., van Merrienboer, J., \& Paas, F. (1998). Cognitive architecture and instructional design. Educational Psychology Review, 10, 251e296. doi:10.1023/A:1022193728205

Threshold/ISTE Youth Forum (2004) Future chat. Threshold. $<$ http://www.ciconline.com/NR/rdonlyres/e4z3cf2ylkjj6o5jnjpdr5pvs rh6okzwx5fokgw5slt2idy6om36rff4bzfusqrhqhhdt2ry7sbnjrggxv3nn f5kz2h/T-Sum-04-FutureChat.pdf >

W. van der Molen., H. Juliette., \& van der Voort, T. (1997). Children's recall of television and print news: A media comparison study. Journal of Educational Psychology, 89, 82-91. doi:10.1037/0022-0663.89.1.82

W. van der Molen., H. Juliette., \& van der Voort, T. (2000). Children's and adults' recall of television and print news in children's and adult news formats. Communication Research, 27, 132-160.

Wouters, P., Paas, F., \& van Merriënboer, J. G. (2010). Observational learning from animated models: Effects of studying-practicing alternation and illusion of control on transfer. Instructional Science, 38, 89-104. doi:10.1007/s11251-008-9079-0

Wouters, P., Tabbers, H., \& Paas, F. (2007). Interactivity in videobased models. Educational Psychology Review, 19, 327-342. doi:10.1007/s10648-007-9045-4

Wetzel, C. D., Radtke, P. H., \& Stern, H. (1994). Instructional effectiveness of video media. Hillsdale, NJ: Erlbaum. 